\title{
Measurement of MIcroscale Residual Stresses in Multi-Phase Ceramic Composites Using Raman Spectroscopy
}

\author{
Phillip Jannotti ${ }^{1,2}$, Ghatu Subhash ${ }^{1}$, James Zheng ${ }^{3}$, and Virginia Halls ${ }^{3}$ \\ ${ }^{1}$ Department of Mechanical and Aerospace Engineering, Gainesville, FL 32611 \\ ${ }^{2}$ U.S. Army Research Laboratory, Aberdeen Proving Ground, MD 21005 \\ ${ }^{3}$ Program Executive Office—Solider, U.S. Army, Fort Belvoir, VA 22060, USA
}

\begin{abstract}
A methodology is described for characterizing the spatial distribution of thermal mismatch stresses at grain level in $\mathrm{B}_{4} \mathrm{C}-\mathrm{SiC}-\mathrm{Si}$ ceramic composites using Raman spectroscopy. Unlike traditional methods to detect residual stress (e.g., X-ray diffraction) which provide average values over the entire specimen surface, Raman peak-shift analysis provides residual stress distributions within the microstructure at high spatial resolution. While the classical formulation predicts uniform compressive stress within a Si-phase surrounded by the ceramic matrix, the Raman measurements revealed non-uniform residual stress distributions in $\mathrm{Si}$ when the particle size was larger than 5 microns. For large irregular shaped particles, the two methods coincide only along the interface between the particle and matrix, but vary drastically both in magnitude and nature in the interior of the particle where large tensile stresses have been measured. The average residual stress within the microstructure was found to correlate well with the volume fraction of the constituents and material properties. The presence of anomalous tensile stress in the interior of the minor Si-phase results in defect generation and structural disorder which has been confirmed by a subsequent TEM analysis.

Corresponding Author: G. Subhash (subhash@ufl.edu), ph: 352-392-7005, f: 352-392-7303 Keywords: Raman spectroscopy, boron carbide, silicon carbide, residual stress, reaction bonding
\end{abstract}




\section{Introduction}

Structural ceramics, such as boron carbide $\left(\mathrm{B}_{4} \mathrm{C}\right)$ and silicon carbide $(\mathrm{SiC})$, offer exceptional mechanical properties and have applications ranging from lightweight armor to wear-resistant tooling [1-3]. These ceramics are commonly produced by hot pressing or

pressureless sintering. Recently, reaction bonding has become a promising alternative because it offers rapid fabrication times, reduced processing temperatures, and can produce complex, near net-shape parts [4], e.g., a one-piece ceramic helicopter seat [5,6]. In this method, a porous ceramic $\left(\mathrm{B}_{4} \mathrm{C}\right.$ and/or $\left.\mathrm{SiC}\right)$ powder preform is placed in a vacuum furnace along with Si lumps. As the temperature is raised above the melting point of silicon $\left(1410^{\circ} \mathrm{C}\right)$, the molten silicon $(\mathrm{Si})$ infiltrates the ceramic preform [7] and reacts with a carbon (C) source (free carbon or residual carbon in $\mathrm{B}_{4} \mathrm{C}$ ) to form $\mathrm{SiC}$. The reaction-formed $\mathrm{SiC}$ and residual (unreacted) $\mathrm{Si}$ bond the microstructure together. Due to the complex microstructure of reaction bonded ceramics, an indepth understanding of microstructure-property relationships is crucial for their effective use in intended applications.

An important consideration in these multiphase ceramic composites processed at high temperatures is residual misfit stress that evolves due to coefficient of thermal expansion mismatch and in some cases, even defect generation [8]. Patent literature [9] has revealed that residual compressive stresses in the Si phase can be leveraged as a "toughening" mechanism. Because $\mathrm{Si}$ is the weakest mechanical constituent in the composite microstructure it is of utmost interest in this study $[10,11]$.

The current work is motivated by three considerations: (i) Limited work has been reported on thermal mismatch stresses in reaction bonded materials, especially at microstructural level; (ii) A method for evaluating the spatial distribution of stress across different phases of 
varying size and shape is not readily available. Such an effort is critically important to understand the failure behavior of multi-phase composites. Traditional techniques to measure residual stresses, such as X-ray diffraction, yield only global average values and cannot provide stress distributions at the micron-scale with high spatial resolution. Lastly, (iii) classical formulation for calculation of residual stress in a small region (or a particle) surrounded by semiinfinite matrix assumes a perfect spherical geometry and uniform residual stress within the particle. In reality, these particles occur in various shapes and sizes, and the residual stress within the particles cannot be assumed constant. In this manuscript, a methodology is described to quantify the magnitude and spatial districution of residual stress at micron-scale spatial resolution using micro-Raman spectroscopy on the $\mathrm{Si}$ phase of the reaction bonded $\mathrm{B}_{4} \mathrm{C}$ and $\mathrm{SiC}$ ceramics. Transmission electron microscopy (TEM) was then used to identify structural disorder resulting from these stresses.

\section{Experimental}

\subsection{Materials and Microstructure}

Three reaction bonded ceramics (see Table 1), with a naming convention based on starting powder composition, were examined: (i) $\mathrm{B}_{4} \mathrm{C}$ powder ( $\mathrm{BC}$ ceramic), (ii) $\mathrm{B}_{4} \mathrm{C}-\mathrm{SiC}$ powders (BSC ceramic), and (iii) $\mathrm{SiC}$ powder ( $\mathrm{SC}$ ceramic). Two types of BC ceramics were assessed: one contained only $\mathrm{B}_{4} \mathrm{C}$ particles with no preform additives (BC-1) and the other contained $10 \mathrm{wt} \%$ of diamond particles (BC-D) in the preform as an additional carbon source to reduce the residual Si content [12]. Three $\mathrm{BSC}$ ceramics with varying ratios of $\mathrm{B}_{4} \mathrm{C}$ and $\alpha-\mathrm{SiC}$ powders (BSC-1, BSC-2, and BSC-3) were used. Finally, the SC ceramic containing only $\alpha-S i C$ powder in the preform (called SC-1). After reaction bonding, the final ceramic compositions are reported in volume percentage (vol.\%) as shown in Table 1. Exact details of the process 
parameters were proprietary and only the starting and final compositions were revealed by the manufacturer.

The typical microstructure for each type of reaction bonded ceramics is shown in Fig. 1. Raman spectroscopy was used for identification of phases present based on characteristic Raman peaks shown in Fig. 1(d). The residual Si phase has one strong peak at $520 \mathrm{~cm}^{-1}$, with a broad spectral feature at $965 \mathrm{~cm}^{-1}$ [13]. The SiC polytypes found in the reaction bonded ceramics are $\alpha$ $\mathrm{SiC}$ and $\beta$-SiC. The $\alpha-\mathrm{SiC}$ (the starting powder) exhibits peaks at 769, 789, 798, and $971 \mathrm{~cm}^{-1}$, while the peaks of $\beta$-SiC (reaction formed) are at 793 and $973 \mathrm{~cm}^{-1}[14,15]$. The $\alpha$-SiC appears as polygonal-shaped grains, while $\beta$-SiC appears as needle-like whiskers (see Fig. 1(a)). The $\mathrm{B}_{4} \mathrm{C}$ has a multitude of peaks between $200-1200 \mathrm{~cm}^{-1}$, specifically 264,324 , and $1090 \mathrm{~cm}^{-1}[16,17]$.

\subsection{Raman Spectroscopy}

A Raman spectroscope (Renishaw InVia, 532 nm laser, 1 micron spatial resolution) was used to evaluate thermal stresses and structural disorder in the ceramic composites. Raman spectroscopy utilizes a focused laser to probe a specific region in a material. The laser light is scattered by the material causing an increase or decrease in energy which is characteristic of specific molecular vibration modes and chemical bonds $[18,19]$. The shifts in energy are interpreted and visualized as specific peaks in the collected spectra. To prevent localized heating of scanned regions, a low laser power of $10 \mathrm{~mW}$ was used.

Silicon was chosen for analysis because it is the weakest constituent in the microstructure. Raman spectral scans were collected from pure Si powder (reference material used for calibration), Si lumps used for reaction bonding (obtained from manufacturer), and Si regions within the reaction bonded ceramics. The characteristic stress-free peak at $520 \mathrm{~cm}^{-1}$ of Si was used as the reference and chosen for analysis. Peak shifts relative to this position were 
related to residual stress, while peak broadening and reduced peak intensity were related to structural disorder [20]. In numerous Raman spectroscopic investigations, the shift $(\Delta w)$ in the position of the most dominant Si peak from the virgin state $\left(520 \mathrm{~cm}^{-1}\right)$ to stressed state was related to residual stress $\left(\sigma_{S i}\right)$ as [21-23]:

$$
\sigma_{S i}=-250(\Delta w)\{\mathrm{MPa}\}
$$

When the local residual stress is larger than the yield strength of the material, defects may be nucleated. Strain associated with structural disorder can cause peak asymmetry and peak broadening in the Raman spectrum which was then monitored for further analysis.

\subsection{Transmission Electron Microscopy (TEM)}

To corroborate peak asymmetry and broadening in the Raman spectrum to the structural disorder in the processed material, TEM analysis was undertaken on raw Si used for infiltration (prior to reaction bonding) and on $\mathrm{Si}$ in the reaction bonded $\mathrm{BC}-1$. The TEM samples were prepared using a focused ion beam (FEI Dual-Beam Strata DB235) and were observed in a fieldemission TEM (JEOL 2010F, Peabody, MA, USA).

\subsection{Mechanical Properties}

Static indentation hardness measurements were conducted with a standard hardness tester (Wilson ${ }^{\circledR}$ Instruments Tukon $\left.{ }^{\mathrm{TM}} 2100 \mathrm{~B}\right)$ on the ceramic composites using Vickers and Knoop indentations at $1 \mathrm{~kg}$ and $2 \mathrm{~kg}$, respectively. The indentation loads were chosen to generate measurable indents and minimal cracking. At least 30 indentations were performed on several samples to generate a representative average value. All indentations were measured using an optical microscope (Olympus model BX51).

Uniaxial compression experiments were performed using 3.4 x 3.4 x 5 mm rectangular bar specimens with their surfaces polished to a 15-micron finish. Quasi-static testing was 
conducted in a servo-hydraulic testing machine (MTS model 309.2) at two nominal strain rates of $5 \times 10^{-3}$ and $5 \times 10^{-4} \mathrm{~s}^{-1}$. The dynamic experiments were conducted using a split Hopkinson pressure bar (SHPB) suitably modified for testing ceramics at a nominal strain rate of $10^{3} \mathrm{~s}^{-1}$ [24]. The incident and transmission bars were made of maraging steel and were $19 \mathrm{~mm}$ in diameter, and $1219 \mathrm{~mm}$ and $914 \mathrm{~mm}$ in length, respectively. Impedance-matched tungsten carbide platens of $12.7 \mathrm{~mm}$ diameter and $9.5 \mathrm{~mm}$ height were used to protect the loading surfaces from indentation by the intact or failed ceramic fragments during testing. The platen surfaces in contact with test specimens were lubricated to eliminate frictional effects and ensure a uniform stress state in the specimen. Ten specimens of each material were tested at each strain rate.

\section{Theoretical Estimation of Residual Stress}

If the microstructure is assumed to be an assembly of uniformly sized, elastic, spherical Si particles $(p)$ surrounded by a semi-infinite ceramic $\left(\mathrm{B}_{4} \mathrm{C}\right.$ or $\left.\mathrm{SiC}\right)$ matrix $(m)$, the magnitude of residual stress $(\sigma)$ in Si regions can be approximated using the following classical equation [25],

$$
\sigma_{m-p}=-\frac{\Delta \alpha \cdot \Delta T}{\left[\frac{0.5\left(1+v_{m}\right)+f_{p}\left(1-2 v_{m}\right)}{E_{m}\left(1-f_{p}\right)}+\frac{1-2 v_{p}}{E_{p}}\right]}
$$

where the misfit stress developed in the particle is a function of the difference $(\Delta T)$ between processing and ambient temperatures, elastic modulus $(E)$ and Poisson's ratio $(v)$, the coefficient of thermal expansion (CTE) mismatch $\left(\Delta \alpha=\alpha_{m}-\alpha_{p}\right)$ between the matrix and particle phases, and the volume fraction of particle phase $\left(f_{p}\right)$. Although Eq. (2) is derived for a two-phase composite, a multi-phase material microstructure can be discretized into localized regions of two-phase materials. Thus, one can compute the thermal mismatch stress between each combination of matrix and particle phases (e.g., $\mathrm{B}_{4} \mathrm{C}-\mathrm{Si}$ and $\mathrm{SiC}-\mathrm{Si}$ mismatches) as shown in Table 2. The CTE for $\mathrm{B}_{4} \mathrm{C}, \mathrm{SiC}$, and $\mathrm{Si}$ are approximately $6.0,4.6$, and $3.6 \times 10^{-6} /{ }^{\circ} \mathrm{C}$, 
respectively (i.e., $\alpha_{B_{4} C}>\alpha_{S i C}>\alpha_{S i}$ ). The elastic moduli and Poisson's ratios of $\mathrm{B}_{4} \mathrm{C}$ and $\mathrm{SiC}$ are very similar and taken to be $\sim 450 \mathrm{GPa}[1,26-33]$ and 0.17 [1,26,28-30,33,34], respectively, and for Si these values are taken to be $150 \mathrm{GPa}[26,35,36]$ and $0.22[26,35]$, respectively. Using a nominal volume fraction of Si phase of $20 \%$ (e.g., BC-1 and SC-1) for illustrative purposes, the predicted values of residual stress in $\mathrm{B}_{4} \mathrm{C}-\mathrm{Si}$, SiC-Si, and $\mathrm{B}_{4} \mathrm{C}-\mathrm{SiC}$ would be 583, 243, and 563 $\mathrm{MPa}$, respectively. This value can be compression or tension depending on the phase in consideration, i.e., whether the phase being considered has higher or lower CTE than the adjacent phase. The actual stress developed in each region and each phase differs based on local volume fraction of particle phase, properties of the surrounding phase, and the size and shape of the particle.

Based on Eq. (2), as the composite is cooled from processing temperature down to ambient temperature, a matrix phase with higher CTE than the particle $\left(\alpha_{m}>\alpha_{p}\right)$ should shrink more, placing the low CTE particle in residual compression, while the matrix is left in tension. The opposite is true for a matrix with lower CTE than the particle $\left(\alpha_{m}<\alpha_{p}\right)$, where the particle is left in tension and the matrix is placed in compression. Thus, Si is expected to always be in residual compression. Furthermore, the largest beneficial compressive stress would develop in $\mathrm{Si}$ for primarily $\mathrm{B}_{4} \mathrm{C}$-containing ceramics ( $\mathrm{BC}$ and $\mathrm{BSC}$ ) due to large $\mathrm{B}_{4} \mathrm{C}$-Si thermal mismatch, compared to lesser SiC-Si thermal mismatch in predominantly SiC-containing ceramics (SC). Large residual compressive stresses should be beneficial in improving mechanical performance, but understanding their spatial distribution and variation will be of primary importance.

Recall that because Eq. (2) only provides residual stress between two phases, it must be suitably modified for multi-phase materials. We assume that the microstructure can be discretized into local regions of two phase materials and then weigh the resulting mismatch stress 
between $\mathrm{B}_{4} \mathrm{C}-\mathrm{Si}$ or $\mathrm{SiC}-\mathrm{Si}$ according to relative volume fraction of each contributing mismatch. Thus, the stress in any one phase becomes a weighted average of the stress due to its mismatch with the other two phases and is calculated as

$$
\sigma_{i}=\frac{1}{f_{j}+f_{k}}\left(f_{\mathrm{j}} * \sigma_{i-j}+f_{\mathrm{k}} * \sigma_{i-k}\right)
$$

where $i, j$, and $k$ take the values 1,2 and 3. For example, the stress in phase $1\left(\sigma_{1}\right)$ is a weighted average of the stress developed due to mismatch between phases 1-2 and between 1-3 (i.e., $\sigma_{1-2}$ and $\sigma_{1-3}$ given by Eq. (2)). The sign of the stress value for each phase is assigned based on the CTE values of included phases (known a priori). A major assumption is that the local volume fraction in the region being analyzed is the same as the global average volume fraction value being used. Also, it is assumed a larger area can be discretized into localized regions of twophase materials. Thus, based on relative quantities of one phase compared to another, a residual stress value can be determined for any phase in a multi-phase material as shown in Table 3. For regions with highly irregular particles it is unrealistic to assume uniformity in residual stresses with in each particle as will be demonstrated by Raman peak shift.

\section{Results and Discussion}

\section{1 Residual Stress}

The vast differences in thermo-mechanical properties of $\mathrm{B}_{4} \mathrm{C}, \mathrm{SiC}$, and $\mathrm{Si}$, shown in Table 2, cause thermal residual stress in the microstructure. Because residual Si is the weakest mechanical phase in the composite, it was of utmost interest in this analysis. Shown in Fig. 2 are Raman spectra for a silicon standard (reference material), raw Si used for infiltration (prior to reaction bonding) in its bulk and powder form, and selected scans of residual $\mathrm{Si}$ in a reaction bonded ceramic with predominantly $\mathrm{B}_{4} \mathrm{C}, \mathrm{BC}-1$, due to greater anticipated peak shifting (higher 
mismatch and residual stress). Both the Si standard and bulk Si show a high intensity sharp (narrow line width) peak at $520 \mathrm{~cm}^{-1}$, representing high-crystalline quality and negligible residual stress, respectively. The bulk $\mathrm{Si}$ was powdered, and was re-scanned (to verify its stressfree condition). The same strong, narrow peak at $520 \mathrm{~cm}^{-1}$ was observed, suggesting negligible stress and structural disorder prior to processing. On the contrary, residual silicon in the reaction bonded ceramic showed observable peak shifting due to residual stress as well as peak broadening, reduced peak intensity, and peak asymmetry likely due to defects generated during processing.

Recall from Table 2 that Si exhibits lower coefficient of thermal expansion (CTE) than $\mathrm{B}_{4} \mathrm{C}$ and $\mathrm{SiC}$. Thus, as the ceramic composite cools after reaction bonding the carbide phases shrink more than $\mathrm{Si}$, placing $\mathrm{Si}$ in residual compression and causing Raman peak shifts to higher wavenumbers. Using Eq. (2), for a spherical Si region encased in $\mathrm{B}_{4} \mathrm{C}$ matrix, it was predicted that a uniform compressive stress up to around -583 MPa would develop in $\mathrm{Si}$ (see Table 2), i.e., the peak would shift to higher wavenumbers (compression) everywhere in the Si region. However, based on experimentally observed peak shifts for the perimeter and interior regions of a typical Si region in the final ceramic (Fig. 2), it was seen that the Si peak shifted to higher wavenumbers (compression) in perimeter regions and to lower wavenumbers (tension) in interior regions. These peak shifts suggest non-uniformities in the stress state within each particle, contrary to the predictions of uniform compressive stress by the classical formulation (Eq. (2)). To determine the range of validity of classical formulation and to better understand the nature of residual stress developed, Si regions of varying size and shape were investigated (see Fig. 3). Raman maps scans were conducted using a 100X objective and encompassed only a single Si region in each scan. The collected Raman maps were color-coded and analyzed as a function of 
peak position, to create a residual stress map (Figs. 3 and 4). It was found that Si regions smaller than $\sim 5 \mu \mathrm{m}$ in size were in a state of uniform compression as shown in Fig. 3(a) but those larger than $5 \mu \mathrm{m}$ and of irregular shape revealed an anomalous tensile stress (see Fig. 3(b-d)) in the interior of the Si phase. This observation was accompanied by increased stress non-uniformity (indicated by color gradation) in both the perimeter compression and interior tension.

The predicted compressive stress value of -583 MPa (with Eq. (2)), compared well with magnitude of residual compressive stress measured in small regions (Figs. 3(a-b)) or along the periphery of large Si regions (Fig. 3(c-d)) between -575 to -590 MPa. Recall that Eq. (2) assumes a two phase material with spherical particle surrounded by a semi-infinite matrix and predicts a uniform state of compression in the Si regions. Clearly, the small Si regions better matched the predictions because they represented the ideal case. However, as particle size and shape deviated from the ideal case, experimentally measured stresses deviates from the predicted values. Thus, the Raman technique not only measures the theoretically predicted residual stresses (in ideal microstructures) but also sheds light on the unforeseen microscale stress heterogeneities, i.e., interior tensile stresses in highly irregular and large size particles.

The reasons for non-uniform stress distribution and tensile stress in Si particles can be rationalized as follows: (i) For a large particle, the exterior region cools more rapidly than the interior, and as a result, the exterior is in compression and interior is in tension; (ii) The irregular shape of the particle induces non-hydrostatic stress state on the particle resulting in high magnitude of shear and tensile stresses at various points within the particle; and finally, (iii) the $\mathrm{Si}$ is surrounded by ceramic particles of different sizes with different crystallographic orientations, and as is well known the elastic modulus and the CTE differ in each orientation resulting in uneven application of compressive stress on the Si phase boundary. All these factors 
can contribute to the development of stress non-uniformities, interior balancing tension, and appreciable gradients in the developed stress state.

With this knowledge, it was of interest to assess the influence of the surrounding ceramic phase (either $\mathrm{B}_{4} \mathrm{C}$ or $\mathrm{SiC}$ ) on the thermal stress developed in $\mathrm{Si}$ phase of a multicomponent ceramic composite. Raman maps were obtained for silicon regions when surrounded primarily by either $\mathrm{B}_{4} \mathrm{C}$ or $\mathrm{SiC}$, as shown in Figs. 4(a) and 4(b), respectively. Based on the first-order approximation of thermal stress (Eq. (2)) for Si encased solely in $\mathrm{B}_{4} \mathrm{C}$ matrix, it was predicted that compressive stress up to -583 MPa would develop in Si. Experimentally, for a Si region surrounded solely by $\mathrm{B}_{4} \mathrm{C}$ (BC ceramic; $\left.\mathrm{BC}-1\right)$, it was observed that residual compression was on average -390 MPa, reaching up to -590 MPa on the periphery depending on size and shape of particles considered. Conversely, the average tensile stress was $+80 \mathrm{MPa}$, with stresses up to +320 MPa in the interior. When Si is encased by only SiC, a residual compression of -243 MPa was predicted (see Table 2). Similarly, for a Si region surrounded solely by SiC (SC ceramic; SC-1), stress non-uniformities similar to that observed for BC ceramic were observed. Again, the interior was found in a state of residual tension, while the perimeter was in compression. The average level of residual compressive stress was $-50 \mathrm{MPa}$, with stress up to $-260 \mathrm{MPa}$ at the periphery of the Si region. On average, the tensile stresses were around +104 MPa, reaching up to $+530 \mathrm{MPa}$ in the Si interior. Thus, due to lower CTE mismatch between Si and SiC (compared to $\mathrm{Si}$ and $\mathrm{B}_{4} \mathrm{C}$ ), lower levels of residual compressive stresses were developed.

Clearly, in both examples above, the Raman technique was not only able to accurately measure the maximum residual compressive stress near the Si periphery, but also identified stress non-uniformities which deviated from the classical formulation. In order to expand the utility of this method and examine compositional influences on the developed stresses in more 
complex ceramic composites, large areas consisting of many Si regions of varying sizes and shapes were examined to sufficiently account for microscale heterogeneities: $2100-10,600 \mu \mathrm{m}^{2}$ of Si or 3,300-16,600 unique Si spectra are collected (depending on volume fraction of Si present in each material). The peak shift value was determined for each collected spectrum and converted into a residual stress value using Eq. (3). The results are summarized in Figs. 5 and 6, which illustrate the distribution of residual stresses for the various compositions.

In Fig. 5, the influence of Si region size/shape and composition are depicted. The larger the Si region, the more non-uniform (greater color variation) the resulting stress distribution, and the greater the interior tension (blue regions). Also, increased $\mathrm{B}_{4} \mathrm{C}$ content resulted in a higher level of compressive stress (i.e., green regions). Notice that outer regions of $\mathrm{BC}$ materials are highly compressive (green), while for the SC material they are mildly compressive (white). In addition to revealing local stress variation, these large map scans allow a single representative stress value to be determined for each material composition. These values can be used to make quantitative comparisons between mechanical properties and average residual stress for various microstructures.

Averaged values of residual stress in Si were extracted from the large maps in Fig. 5 for each material composition and plotted as a function of the volume fraction of various phases in Fig. 6. The data was examined in terms of average compressive stress (average value of all compressive points in Si regions), average tensile stress (average value of all tensile points in $\mathrm{Si}$ regions), or average residual stress (average value of all points in Si regions). The influence of volume fraction of carbide phase on the stress developed in Si is demonstrated in Figs. 6(a) and 6(b) (see solid green line). It can be noted that the average compressive stress in Si transitions from high compression (-330 to $-445 \mathrm{MPa}$ ) for predominantly $\mathrm{B}_{4} \mathrm{C}$ ceramics $(\mathrm{BC})$, to moderate 
compression (-200 to $-350 \mathrm{MPa}$ ) for ceramics with comparable $\mathrm{B}_{4} \mathrm{C} / \mathrm{SiC}$ content (BSC), to weak compression (-50 MPa) for predominantly $\mathrm{SiC}$ ceramics (SC). Because $\mathrm{B}_{4} \mathrm{C}$ has higher thermal mismatch with $\mathrm{Si}$ compared to $\mathrm{SiC}$, increased volume fraction of $\mathrm{B}_{4} \mathrm{C}$ leads to an increased magnitude of residual compression in the Si regions as in Fig. 6(a). It was also observed that average stresses in $\mathrm{Si}$ (see dashed red line) trended from highly compressive (-270 to $-435 \mathrm{MPa}$ ) for $\mathrm{BC}$ materials to mildly tensile ( $+57 \mathrm{MPa}$ ) for $\mathrm{SC}$ materials. The low level of compressive stress in SC materials was overwhelmed by anomalous tensile stresses, leading to an average tensile state of stress. Lastly, the average value of residual tensile stress in each material did not show a strong dependence on $\mathrm{B}_{4} \mathrm{C}$ or $\mathrm{SiC}$ content (see solid blue line in Fig. 6(a-b)).

Interestingly, trends in average stress, average compression, and average tension were observed as strong functions of the vol.\% $\mathrm{Si}$ (see Fig.6(c)). It was noted that increased $\mathrm{Si}$ volume fraction correlated with decreased residual compression (see solid green line) and correspondingly greater residual tension (see solid blue line). As the Si content increased, the size of the Si regions also increased (see Fig. 5) and subsequently a higher likelihood of nonuniform cooling in each Si region. This lead to non-uniform residual stresses with compression only along the periphery and tension in the interior of the large Si regions. When Si volume fraction was low, most of the $\mathrm{Si}$ is in compression and the average stress is highly compressive (see dashed red line in Fig. 6(c)). With increased Si content, more number of large irregular shapes form with high interior tension, and so the average stress became less compressive. This observation is an extension of what was seen for the mapped regions shown in Fig. 3, which demonstrated that smaller Si regions are more likely to develop only compression, while larger Si regions have higher tendency to develop interior tension.

The above experimental results were found to follow the same trend but differ in 
magnitude from the predicted values of stress in Si computed using Eq. (3) (see dotted black lines in Fig. 6(a-c)). The two major differences were: (i) non-existence of tensile stress in the microstructure and (ii) greater compressive stress values from theoretical calculations compared to experimental data. From theoretical calculations (Eq.(3)) it was expected that the thermal mismatch would result only in uniform compression in the Si. However, non-uniformities in the nature and distribution of stress were observed experimentally due to size, shape and surrounding matrix properties. The stress gradients and interior tensile stresses all decrease the level of compressive stress developed in each material with changes in composition. Simply put, if one were to add the average compressive and tensile stress magnitudes found for each material

experimentally, i.e., $\left|\sigma_{c}\right|+\left|\sigma_{t}\right|$, then reasonable agreement is found between the experimental and predicted values. This demonstrates that the discrepancy between experimental and predicted values is primarily due to the fact that the theoretical approximations (assumptions of spherical shape and uniform matrix properties) do not account for the experimental factors such as irregular shape and size, which give rise to local tension.

\subsection{Structural Disorder}

The Raman peak broadening and peak intensity reduction observed in the Si regions of reaction bonded ceramics (see Fig. 2) are commonly related to structural disorder. Similar spectral changes were seen in the interior of Si regions, which have been demonstrated to be in a state of residual tension which can result in lattice strain and structural disorder. Previous work [8] has suggested the development of defects in the Si regions for sufficiently large thermal mismatch. Thus, Raman mapping was carried out to assess the spatial evolution of the Si peak width and peak intensity (see Fig. 7(a-b)) as well as to examine the presence of disorder induced by processing. For brevity, only a Si region surrounded by $\mathrm{B}_{4} \mathrm{C}$ is shown. For the outer 
compressive region, the peak width is narrower at $11-14 \mathrm{~cm}^{-1}$, (i.e., less broadening), compared to interior tensile regions which showed peak widths of $20-30 \mathrm{~cm}^{-1}$ (see Fig. 7(a)). This result suggested more disorder in the interior tensile regions. Additionally, interior Si regions yielded significantly lower intensity (1,500-6,000 counts) compared to the perimeter regions $(10,000$ 20,000 counts) suggesting increased distortion of the Si crystal in the interior (see Fig. 7(b)). Thus, highly compressive regions are expected to have less structural disorder than highly tensile regions. The observed peak broadening and reduced peak intensity are proposed to be due not only to lattice strain but also to high defect generation, i.e., high structural disorder. TEM analysis of Si phase was undertaken to assess the presence of volume defects in a virgin $\mathrm{Si}$ region (taken from a Si lump) and a residual Si region (take from BC-1). Recall that in TEM, defective regions appear dark in contrast against the light background [44].

From Fig, 8(a), it was observed that minimal defectiveness existed in the virgin Si. Only one volume defect could be found in the center of the specimen. On the other hand, the residual Si phase in the reaction bonded ceramic was found to contain a higher concentration of defects (e.g., dislocations and point defects) as seen in Fig. 8(b). Lattice strain due to thermal mismatch led to lattice disorder and some level of defect generation. Because only a finite amount of tensile strain energy can be stored in the lattice, defect generation allows strain relaxation. It would be anticipated that the level of defectiveness would ideally scale with the level of thermal mismatch, suggesting that a higher defect density should prevail in BC ceramics than BSC or SC ceramics.

Additionally, boron (B) and carbon (C) in the starting powder can dissolve into molten $\mathrm{Si}$ during processing leading to residual stress and/or structural disorder. Doping Si with smaller atoms, such as B, results in lattice contraction due to substitution, leading to tensile stresses [45- 
49]. Based on large tensile stresses and disorder observed in interior regions of the Si, increased dopant concentrations would exist primarily in interior regions of the Si. Dopant material (B and/or $\mathrm{C})$ in perimeter regions would likely form reaction phases $\left(\mathrm{B}_{12}(\mathrm{~B}, \mathrm{C}, \mathrm{Si})_{3}\right.$ or $\left.\mathrm{SiC}\right)$ on the boundary of carbide phases [17], leaving remaining dopant concentrated in the interior regions of the residual Si phase. P-type dopants, like B, have also been reported to cause asymmetry in the Si peak and broadening towards higher wavenumbers [19,50,51], similar to that shown in Fig. 2. Additionally, B doping can cause decreased signal intensity [52]. Although, little or no B was detected using energy dispersive spectroscopy (EDS), future studies utilizing compositional analyses which are more sensitive to low concentrations of light elements is warranted.

\subsection{Mechanical Properties}

The average residual stress values in Si, determined using this Raman technique, were compared with the mechanical properties, such as hardness and uniaxial compressive strength, of the composites to determine a link between microstructure (i.e., residual stress) and properties. It is seen from Fig. 9 that compressive strength and hardness are highest when the average residual stress state of the Si phase was highly compressive. As the average residual stress value became increasingly tensile, the mechanical properties were observed to decrease. This observation is consistent with some previous works on brittle materials such as glasses [53] where the residual compressive stress yielded an increase in hardness, and the residual tensile stress resulted in lower hardness values. This result is attributed to the fact that residual compression resists against the indentation loading whereas the residual tension promotes easy penetration and fracture. For uniaxial compressive strength, a similar trend was observed. Greater compressive residual stresses yielded greater fracture strength. At higher strain rates this increase was even steeper. 
Recall that materials with increased vol. $\%$ of $\mathrm{B}_{4} \mathrm{C}$ have greater residual compressive stress than those with equal vol.\% $\mathrm{SiC}$ because of greater thermal mismatch with $\mathrm{Si}$. Also, materials with low Si content and correspondingly small pockets of Si develop high levels of uniform compressive stresses. As the Si vol.\% increased, large irregular pockets developed with interior tension and lower average compression levels. Thus, an ideal reaction bonded ceramic would be $\mathrm{B}_{4} \mathrm{C}$-based with low vol. $\%$ Si to maximize beneficial compressive stress.

Clearly, measuring residual stresses using micro Raman spectroscopy at high spatial resolution allows the composition, microstructure and some properties to be described by a single metric, namely residual stress. Such analysis may enable materials engineers to tailor the microstructure and optimize the mechanical performance. Determination of residual stress at high spatial resolution allows assessment of potential fracture initiation sites in a complex microstructure and can be beneficial in accurate modeling of the process and eventually predict microstructural influences on mechanical properties. In the long run, such knowledge can assist in development of improved processing-structure-property relationships.

\section{Conclusions}

Raman spectroscopy has been effectively used in this investigation to assess residual stress and the level of defectiveness developed in processed multi-phase ceramics. The method provides a convenient route for characterizing local microscale stress heterogeneity at high spatial resolution. It was determined that $\mathrm{Si}$ regions smaller than 5 microns in diameter are in a nearly uniform state of compression as predicted by analytical equations. However, the classical formulation breaks down when the particle size is large or highly irregular, which leads to stress gradients and interior tensile stresses. Raman mapping was also shown to provide the ability to extract a bulk, macroscale residual stress value for a given material. The ability to quantify a 
microstructure or composition and represent it by a single metric allows links to be developed between processing, microstructure and properties. Lastly, Raman peak broadening and intensity reduction in the Si regions, which are indicative of lattice disorder, have been correlated with processing-induced defects through TEM investigation.

\section{Acknowledgements}

Financial support for Phillip Jannotti from the National Defense Science and Engineering Graduate (NDSEG) Fellowship program was provided with Government support awarded by DOD, AirForce Office of Scientific Research, NDSEG, 32 CFR 168a. The authors sincerely acknowledge the support from the Department of Army, US Army RDECOM contract no. W91CRB-10-D-0001-0006.

\section{References}

[1] Thévenot, F. 1990. Boron carbide - A comprehensive review, J Eur Ceram Soc, 6(4):205225.

[2] Pierson HO. Handbook of Refractory Carbides and Nitrides. Westwood, NJ, USA: Noyes Publications, 1996.

[3] Vargas-Gonzalez, L., R. F. Speyer, and J. Campbell. 2010. Flexural strength, fracture toughness, and hardness of silicon carbide and boron carbide armor ceramics, International Journal of Applied Ceramic Technology, 7(5):643-651.

[4] Messner R. P., Y. Chiang. 2008. Processing of Reaction-Bonded Silicon Carbide Without Residual Silicon Phase. In: Proceedings of the 12th Annual Conference on Composites and Advanced Ceramic Materials: Ceramic Engineering and Science Proceedings, John Wiley \& 
Sons, Inc., pp. 1053-1059.

[5] Christine, G. 2003. Saving lives with ceramic armor, Ceram IndJuly 2014.

[6] M-Cubed Technologies. Vehicle Defense Products, http://www.mmmt.com/products/defense/vehicle/, 2014

[7] Karandikar P. G., S. Wong, G. Evans, and M. K. Aghajanian. 2010. Microstructural Development and Phase Changes in Reaction Bonded Boron Carbide. In: Advances in Ceramics Armor VI, Swab J. J., S. Mathur, andT. Ohjieds. Hoboken, NJ, USA: Wiley, pp. 251-259.

[8] Aghajanian M. K., B. N. Morgan, J. R. Singh, J. Mears, and R. A. Wolffe. 2002. A New Family of Reaction Bonded Ceramics for Armor Applications. In: Ceramic Materials by Design, McCauley J. W., A. Crowson, W. A. Gooch Jr et al.eds. Westerville, OH, USA: American Ceramic Society, pp. 527-540.

[9] Aghajanian, M. K. 2006. Toughness enhanced silicon-containing composite bodies, and methods for making same, US Patent 6,995,103

[10] Chhillar P., M. K. Aghajanian, D. D. Marchant, R. A. Haber, and M. Sennett. 2009. The Effect of Si Content on the Properties of B4C-SiC-Si Composites. In: Advances in Ceramic Armor III: Ceramic and Engineering Science Proceedings, Volume 28, Issue 5, John Wiley \& Sons, Inc., pp. 161-167.

[11] Marshall A. L., P. Chhillar, P. Karandikar, A. McCormick, and M. K. Aghajanian. 2009. The Effects of Si Content and SiC Polytype on the Microstructure and Properties of RBSC. In: Mechanical Properties and Processing of Ceramic Binary, Ternary, and Composite Systems: Ceramic Engineering and Science Proceedings, Volume 29, Issue 2, John Wiley \& Sons, Inc., pp. 115-126. 
[12] Karandikar, P. and S. Wong. 2012. Development of reaction bonded B4C- Diamond composites, Advances in Ceramic Armor VIII: Ceramic Engineering and Science Proceedings, 573219.

[13] Parker, J., D. Feldman, and M. Ashkin. 1967. Raman scattering by silicon and germanium, Physical Rev, 155(3):712-714.

[14] Nienhaus, H., T. Kampen, and W. Mönch. 1995. Phonons in 3C-, 4H-, and 6H-SiC, Surf Sci, 324(1):L328-L332.

[15] Nakashima, S. and H. Harima. 1997. Raman investigation of SiC polytypes, physica status solidi (a), 162(1):39-64.

[16] Kunka, C., A. Awasthi, and G. Subhash. 2016. Crystallographic and spectral equivalence of boron-carbide polymorphs, Scr.Mater., 12282-85.

[17] Jannotti, P., G. Subhash, J. Q. Zheng, V. Halls, P. G. Karandikar, S. Salamone et al. 2015. Raman spectroscopic characterization of the core-rim structure in reaction bonded boron carbide ceramics, Appl.Phys.Lett., 106(4):041903.

[18] Popp, J. and W. Kiefer. 2006. Raman scattering, fundamentals, Encyclopedia of Analytical Chemistry

[19] Weber WH, \& Merlin R. Raman Scattering in Materials Science. Springer, 2000.

[20] Sarau, G., A. Bochmann, R. Lewandowska, and S. Christiansen. 2012. From micro-to Macro-Raman spectroscopy: Solar silicon for a case study,

[21] Ganesan, S., A. A. Maradudin, and J. Oitmaa. 1970. A lattice theory of morphic effects in crystals of the diamond structure, Annals of Physics, 56(2):556-594.

[22] Anastassakis, E., A. Pinczuk, E. Burstein, F. H. Pollak, and M. Cardona. 1970. Effect of static uniaxial stress on the raman spectrum of silicon, Solid State Commun., 8(2):133 138. 
[23] Wolf, I. D. 1996. Micro-raman spectroscopy to study local mechanical stress in silicon integrated circuits, Semiconductor Science and Technology, 11(2):139-154.

[24] Subhash G., G. Ravichandran. 2000. Split-Hopkinson Pressure Bar Testing of Ceramics In: ASM Handbook Volume 8, Mechanical Testing and Evaluation, Kuhn H., D. Medlineds. Materials Park, OH: ASM International, pp. 497-504.

[25] Chawla KK. Ceramic Matrix Composites. Boston, MA, USA: Kluwer Academic, 2003.

[26] Sharpe Jr WN, \& Sharpe WN. Springer Handbook of Experimental Solid Mechanics. New York, NY: Springer, 2008.

[27] Hecht, N. L., S. M. Goodrich, L. Chuck, D. McCullum, and V. Tennery. 1992. Mechanical properties characterization of one $\mathrm{SiC}$ and two $\mathrm{Si} 3 \mathrm{~N} 4$ commercially available ceramics, American Ceramic Society Bulletin, 71(4):653-659.

[28] Gettings, R. J. and G. D. Quinn. 1995. Surface crack in flexure (SCF) measurements of the fracture toughness of advanced ceramics, Ceram Eng Sci Proc, 16(4):539-547.

[29] Tracy, C., M. Slavin, and D. Viechnicki. 1988. Ceramic fracture during ballistic impact, Fractography of Glasses and Ceramics Westerville, Ohio, 1988, 22295-306.

[30] Murthy, S. R. 1985. Elastic properties of boron carbide, J.Mater.Sci.Lett., 4(5):603 605.

[31] Gieske, J. H., T. L. Aselage, and D. Emin. 1991. Elastic properties of boron carbides, AIP Conference Proceedings, 231(1):376-379.

[32] Hollenberg, G. W. and G. Walther. 1980. The elastic modulus and fracture of boron carbide, J Am Ceram Soc, 63(11-12):610 613.

[33] With, G. 1984. High temperature fracture of boron carbide: Experiments and simple theoretical models, J.Mater.Sci., 19(2):457 466.

[34] Green, D., J. Hellmann, M. Modest, K. Sikka, and P. Winand. 1990. 'Physical property 
measurements of high temperature composites, Projects Within the Center for Advanced Materials, December 1, 1989 to February 2871-90.

[35] Sharpe, W. N., B. Yuan, R. Vaidyanathan, and R. L. Edwards. 1997. Measurements of young's modulus, poisson's ratio, and tensile strength of polysilicon, 424-429.

[36] Anstis, G. R., P. Chantikul, B. R. Lawn, and D. B. Marshall. 1981. A critical evaluation of indentation techniques for measuring fracture toughness: I, direct crack measurements, J Am Ceram Soc, 64(9):533-538.

[37] Purdue University,Thermophysical Properties Research Center. 1977. Thermal Expansion Non-Metallic Solids. In: Thermophysical Properties of Matter - the TPRC Data Series, Touloukian Y. S., R. K. Kirby, E. R. Taylor, andT. Y. R. Leeds. New York, USA: IFI/Plenum,

[38] Slack, G. A. and S. Bartram. 1975. Thermal expansion of some diamondlike crystals, J.Appl.Phys., 46(1):89-98.

[39] Li, Z. and R. Bradt. 1986. Thermal expansion of the hexagonal (6H) polytype of silicon carbide, J Am Ceram Soc, 69(12):863-866.

[40] Li, Z. and R. Bradt. 1986. Thermal expansion of the cubic (3C) polytype of SiC, J.Mater.Sci., 21(12):4366-4368.

[41] Swenson, C. 1983. Recommended values for the thermal expansivity of silicon from 0 to $1000 \mathrm{~K}$, Journal of physical and chemical reference data, 12(2):179-182.

[42] White, G. and M. Minges. 1997. Thermophysical properties of some key solids: An update, Int.J.Thermophys., 18(5):1269-1327.

[43] Okada, Y. and Y. Tokumaru. 1984. Precise determination of lattice parameter and thermal expansion coefficient of silicon between 300 and 1500 K, J.Appl.Phys., 56(2):314-320. 
[44] Williams, D. B. and C. B. Carter. 2009. Transmission electron microscopy,

[45] Horn, F. H. 1955. Densitometric and electrical investigation of boron in silicon, Physical Review, 97(6):1521.

[46] Queisser, H. 1961. Slip patterns on Boron- Doped silicon surfaces, J.Appl.Phys., 32(9):1776-1780.

[47] Prussin, S. 1961. Generation and distribution of dislocations by solute diffusion, J.Appl.Phys., 32(10):1876-1881.

[48] Pajot, B. and A. Stoneham. 1987. A spectroscopic investigation of the lattice distortion at substitutional sites for groups V and VI donors in silicon, Journal of Physics C: Solid State Physics, 20(32):5241.

[49] Ning, X. 1996. Distribution of residual stresses in boron doped p silicon films, J.Electrochem.Soc., 143(10):3389-3393.

[50] Fano, U. 1961. Effects of configuration interaction on intensities and phase shifts, Physical Review, 124(6):1866.

[51] Nickel, N., P. Lengsfeld, and I. Sieber. 2000. Raman spectroscopy of heavily doped polycrystalline silicon thin films, Physical Review B, 61(23):15558.

[52] Cerdeira, F., T. Fjeldly, and M. Cardona. 1973. Effect of free carriers on zone-center vibrational modes in heavily doped p-type si. II. optical modes, Physical Review B, $8(10): 4734$.

[53] Jannotti, P., G. Subhash, P. Ifju, P. K. Kreski, and A. K. Varshneya. 2012. Influence of ultra-high residual compressive stress on the static and dynamic indentation response of a chemically strengthened glass, J Eur Ceram Soc, 32(8):1551-1559.

[54] Pittari, J., G. Subhash, A. Trachet, J. Zheng, V. Halls, and P. Karandikar. 2015. The rate- 
dependent response of pressureless-sintered and reaction-bonded silicon carbide-based ceramics, International Journal of Applied Ceramic Technology, 12E207-E216.

\section{List of Figure Captions}

Fig. 1. Scanning electron micrographs of the three types of reaction bonded ceramics, where the starting powders were (a) boron carbide (BC), (b) boron carbide and silicon carbide (BSC), and (c) silicon carbide (SC). Phase constituents in the reaction bonded ceramic microstructure were verified by their characteristic Raman peaks given in (d). In the SEM images, the phases can be distinguished by their light/dark contrast, with $\mathrm{B}_{4} \mathrm{C}$ being the darkest grey phase, followed by the residual $\mathrm{Si}$ which is medium grey, and with $\mathrm{SiC}$ being the lightest (almost white) phase.

Fig. 2. Characteristic Raman peaks for the stress-free and as-processed Si phase.

Fig. 3. Residual stress maps for Si regions of varying size and shape in a BC ceramic composite. The inset displays the color-coding based on both Raman peak position and residual stress value. Fig. 4. Residual stress maps based on peak shift in $\mathrm{Si}$ regions surrounded by (a) $\mathrm{B}_{4} \mathrm{C}$ or (b) $\mathrm{SiC}$. Fig. 5. Raman maps color-coded according to (a) phase and (b) residual stress in Si regions. In the phase maps (a), red represents $\mathrm{B}_{4} \mathrm{C}$, green denotes $\mathrm{SiC}$, and blue indicates $\mathrm{Si}$ regions. In the stress maps (b), only the residul Si phase is color-coded, while the other phases are greyed-out. The color-coded legend at the top indicates stress magnitude.

Fig. 6. The average measured residual stress (red line) in Si regions of various reaction bonded ceramics with differing composition given as a function of vol.\% (a) $\mathrm{B}_{4} \mathrm{C}$, (b) $\mathrm{SiC}$, and (c) Si. The average measured stress is split into compressive (green line) and tensile (blue line) components. Also shown is the predicted stress (black line) according to Eq. (3).

Fig. 7. Raman maps of (a) peak width and (b) peak intensity for a Si region surrounded by $\mathrm{B}_{4} \mathrm{C}$. The reduced peak intensity and larger peak width in the interior of the Si regions suggest 
increased structural disorder.

Fig. 8. Bright-field TEM images showing (a) only one defect in virgin Si sample and (b) numerous defects and dislocations in Si of a reaction bonded ceramic (BC-1). Defects are shown in magnified views.

Fig. 9. The influence of average residual stress on indentation hardness (triangle data points) and uniaxial compressive strength (square data points). The blue 'circle' data point was Vickers hardness data taken from Pittari et al. [54]. 


\section{List of Tables}

Table 1. Material compositions in the starting powder preforms and final ceramic composites.

\begin{tabular}{lccccccc}
\hline & \multicolumn{3}{c}{ Preform Composition (wt.\%) } & \multicolumn{3}{c}{ Final Composition (vol.\%) } \\
\hline Material & $\mathrm{B}_{4} \mathrm{C}$ & $\mathrm{SiC}$ & Diamond & $\mathrm{B}_{4} \mathrm{C}$ & $\mathrm{SiC}$ & Diamond & $\mathrm{Si}$ \\
\hline BC-1 & 100 & 0 & 0 & 75 & 8 & 0 & 17 \\
BC-D & 90 & 0 & 10 & 75 & 12 & 4 & 9 \\
BSC-1 & 80 & 20 & 0 & 63 & 27 & 0 & 10 \\
BSC-2 & 80 & 20 & 0 & 63 & 23 & 0 & 14 \\
BSC-3 & 60 & 40 & 0 & 49 & 37 & 0 & 14 \\
SC-1 & 0 & 100 & 0 & 0 & 78 & 0 & 22 \\
\hline
\end{tabular}

Table 2. Selected properties for $\mathrm{B}_{4} \mathrm{C}, \mathrm{SiC}$, and $\mathrm{Si}$.

\begin{tabular}{lccc}
\hline Property & $\mathrm{B}_{4} \mathrm{C}$ & $\mathrm{SiC}$ & $\mathrm{Si}$ \\
\hline Elastic Modulus (GPa) & $372-480$ & $386-460$ & $123-175$ \\
& {$[1,30-33]$} & {$[26-29]$} & {$[26,35,36]$} \\
Poisson's Ratio & $0.14-0.21$ & $0.14-0.17$ & 0.22 \\
Average Coefficient of & {$[1,30,33]$} & {$[26,28,29,34]$} & {$[26,35]$} \\
$\begin{array}{l}\text { Thermal Expansion, CTE } \\
\left(10^{-6} /{ }^{\circ} \mathrm{C}\right)\end{array}$ & 6.0 & 4.6 & 3.6 \\
$\begin{array}{l}\text { Predicted } \mathrm{B}_{4} \mathrm{C}-\mathrm{Si} \text { misfit } \\
\text { stress (Eq. }(2))\end{array}$ & {$[37]$} & {$[34,37-40]$} & {$[37,38,41-43]$} \\
$\begin{array}{l}\text { Predicted SiC-Si misfit } \\
\text { stress (Eq. (2)) }\end{array}$ & +583 & - & -583 \\
$\begin{array}{l}\text { Predicted } \mathrm{B}_{4} \mathrm{C}-\mathrm{SiC} \text { misfit } \\
\text { stress (Eq. (2)) }\end{array}$ & - & +243 & -243 \\
\hline
\end{tabular}

Table 3. Calculated average residual stresses in each phase in the microstructure (Eq. (3)).

\begin{tabular}{cccccccc}
\hline & \multicolumn{2}{c}{ Average vol.\% of Composition } & \multicolumn{3}{c}{ Residual Stress (MPa) } \\
Material & $\mathrm{B}_{4} \mathrm{C}$ & $\mathrm{SiC}$ & Diamond & $\mathrm{Si}$ & $\mathrm{B}_{4} \mathrm{C}$ & $\mathrm{SiC}$ & $\mathrm{Si}$ \\
\hline BC-1 & 75 & 8 & 0 & 17 & +604 & -495 & -545 \\
BC-D & 75 & 12 & 4 & 9 & +613 & -520 & -563 \\
BSC-1 & 63 & 27 & 0 & 10 & +524 & -393 & -496 \\
BSC-2 & 63 & 23 & 0 & 14 & +544 & -384 & -488 \\
BSC-3 & 49 & 37 & 0 & 14 & +448 & -261 & -425 \\
SC-1 & 0 & 78 & 0 & 22 & 0 & +239 & -239 \\
\hline
\end{tabular}



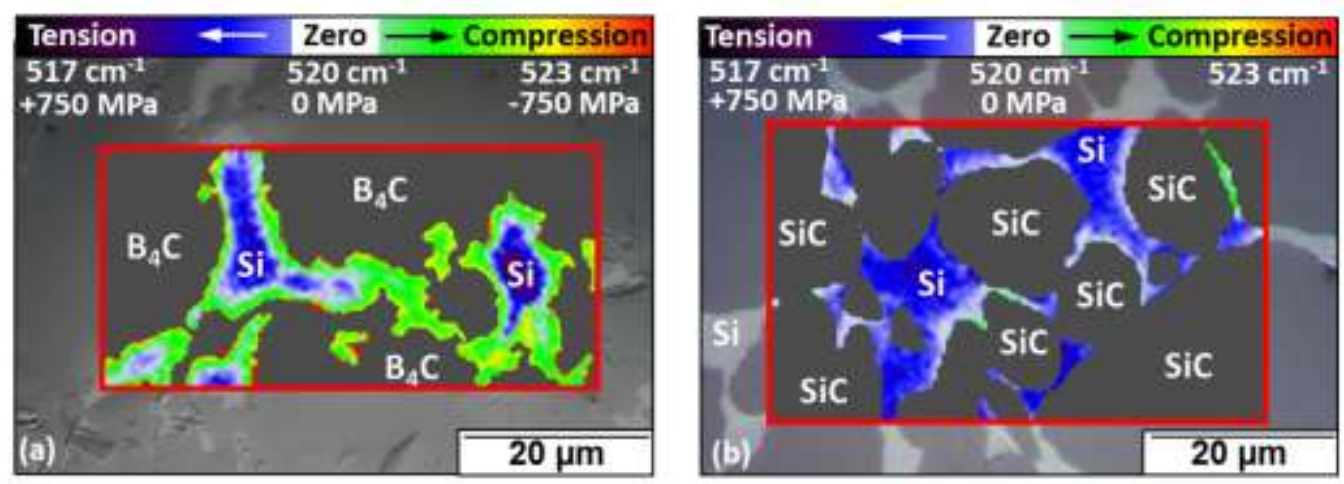

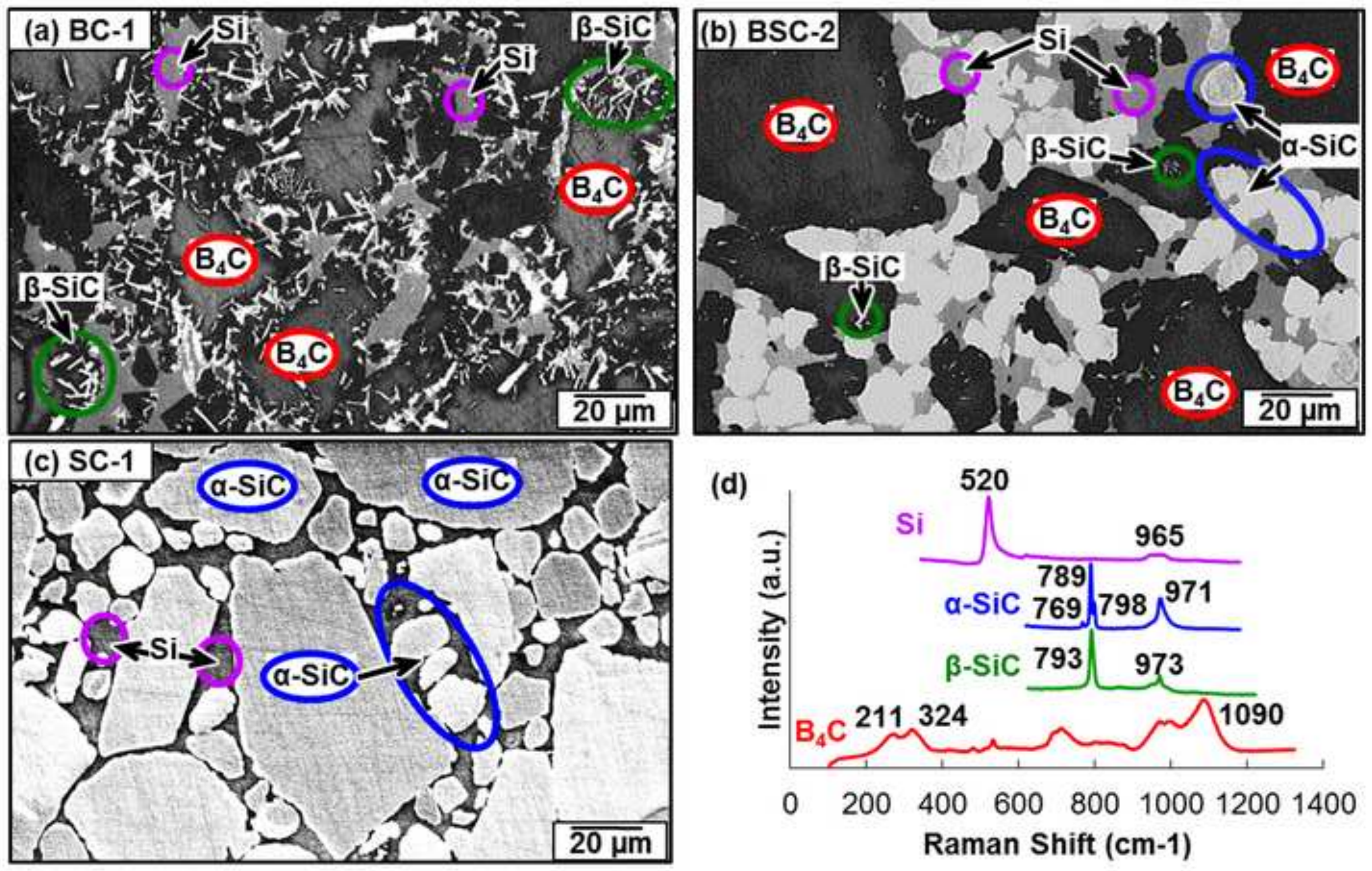

(d)

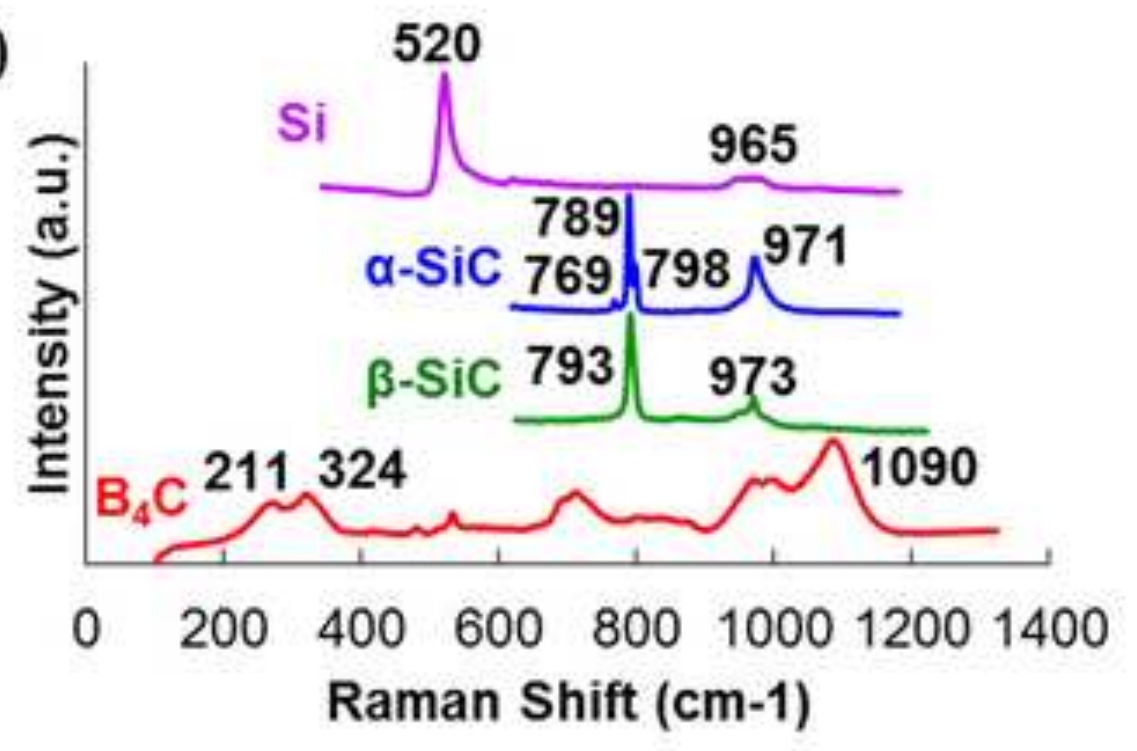




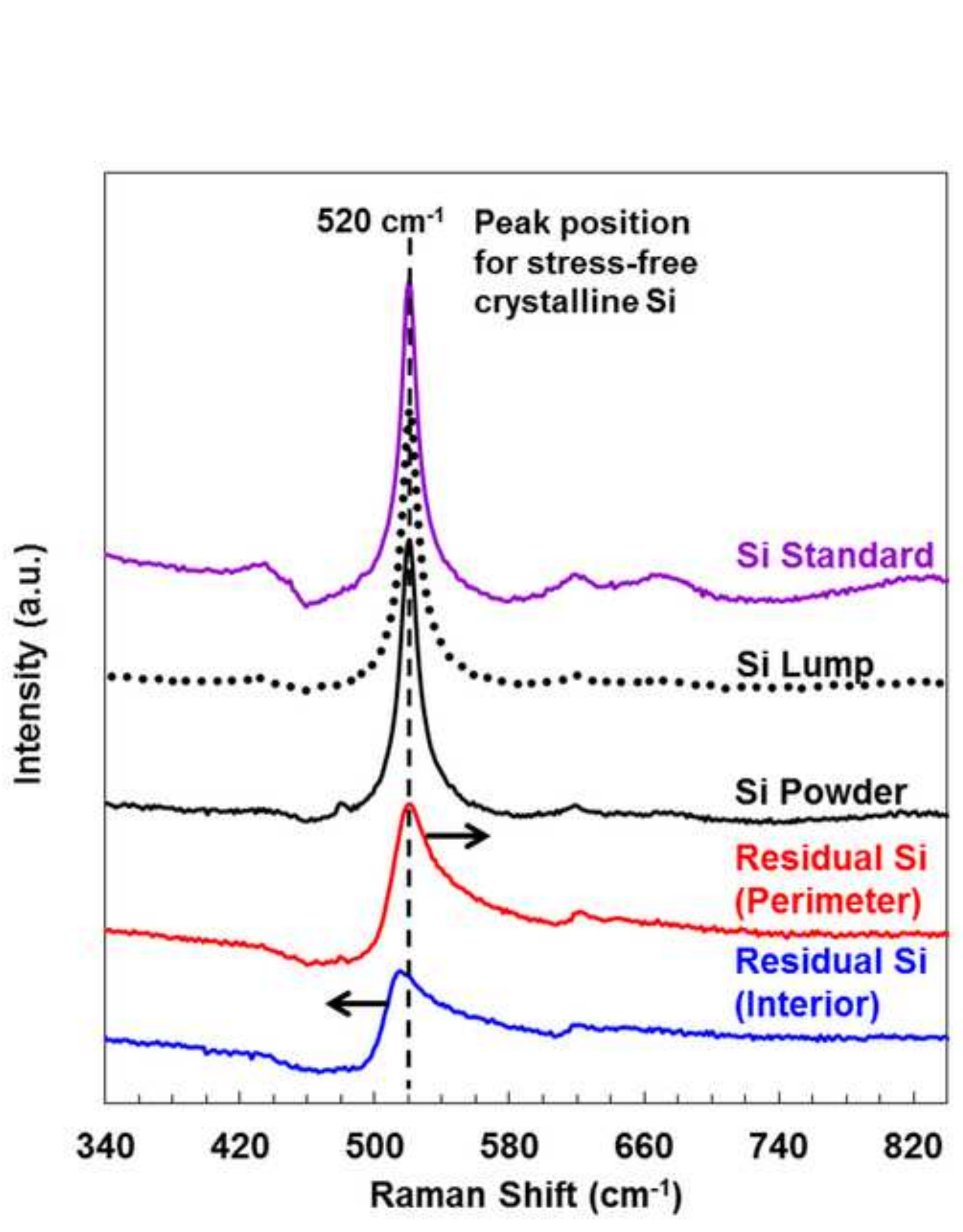

Figure 2

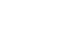

\section{Raman Shift (cm}



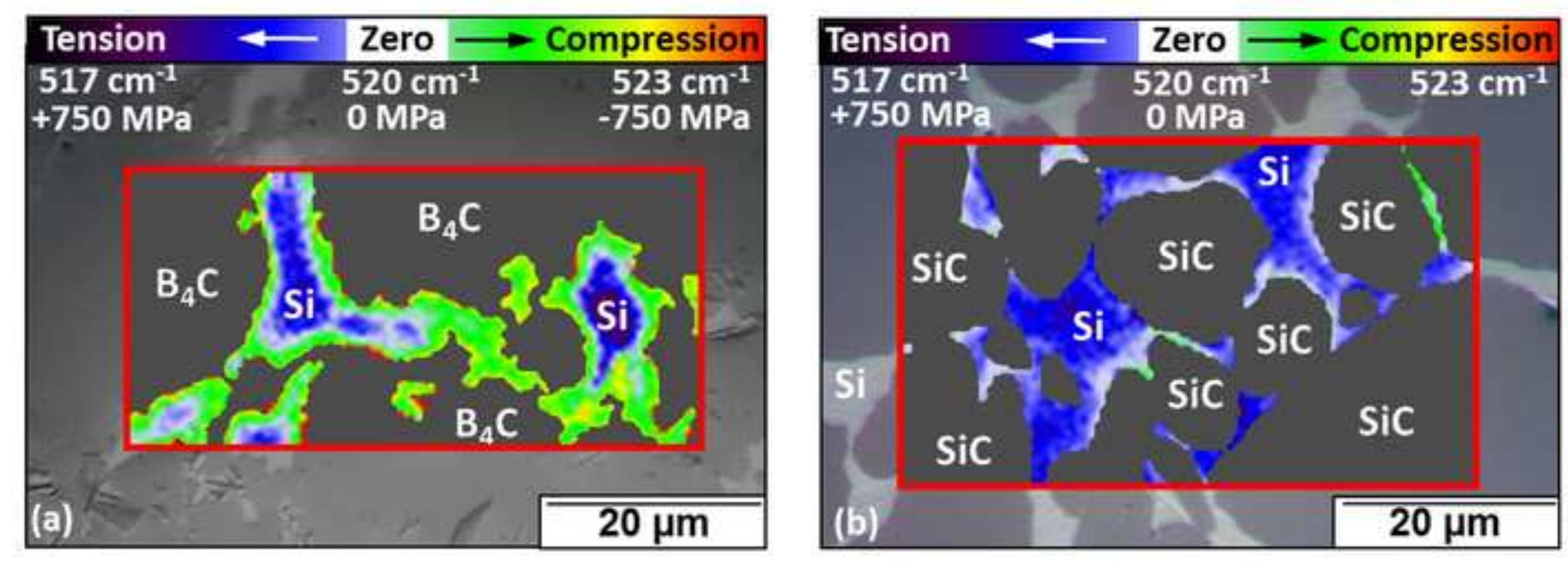
(a) Phase Map

\section{$B_{4} C$}

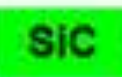

\section{Si}
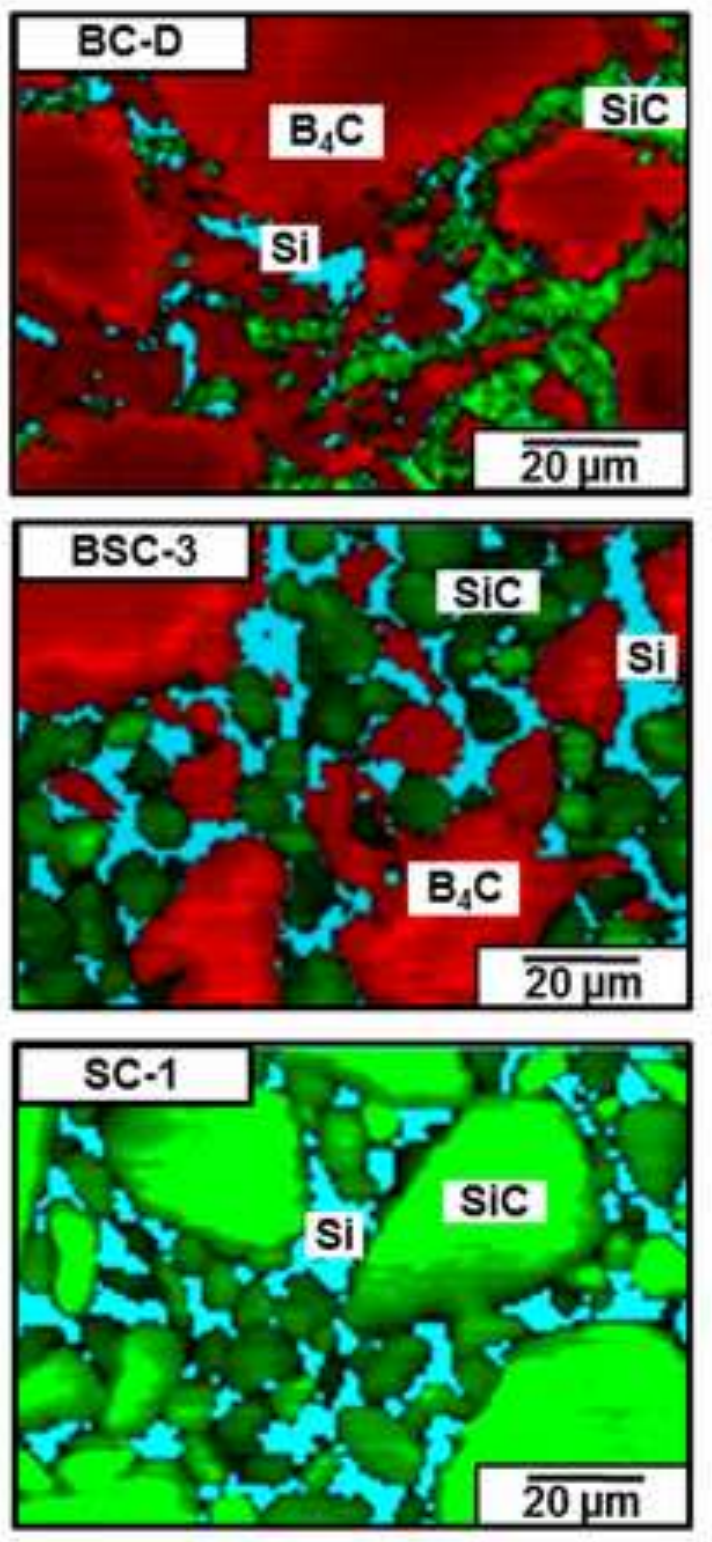

(b) Residual Stress Map

\begin{tabular}{c}
$+750 \mathrm{MPa} \quad 0 \mathrm{MPa} \quad-750 \mathrm{MPa}$ \\
\multicolumn{2}{c}{ Tension $\leftarrow$ Zero $\rightarrow$ Compression } \\
\hline $517 \mathrm{~cm}^{-1} \quad 520 \mathrm{~cm}^{-1} \quad 523 \mathrm{~cm}^{-1}$
\end{tabular}

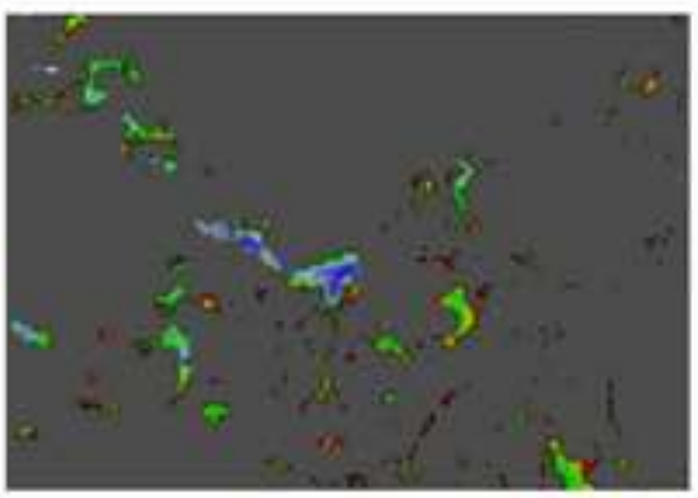

$75 \% \mathrm{~B}_{4} \mathrm{C}$ $12 \% \mathrm{SiC}$

$9 \%$ Si

$<4 \%$ Diamond

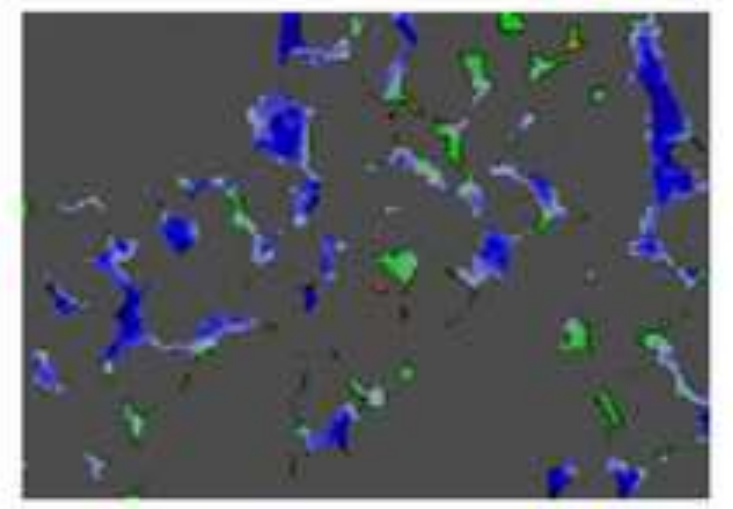

$49 \%$ B 4 C

$37 \%$ SiC

$14 \% \mathrm{Si}$

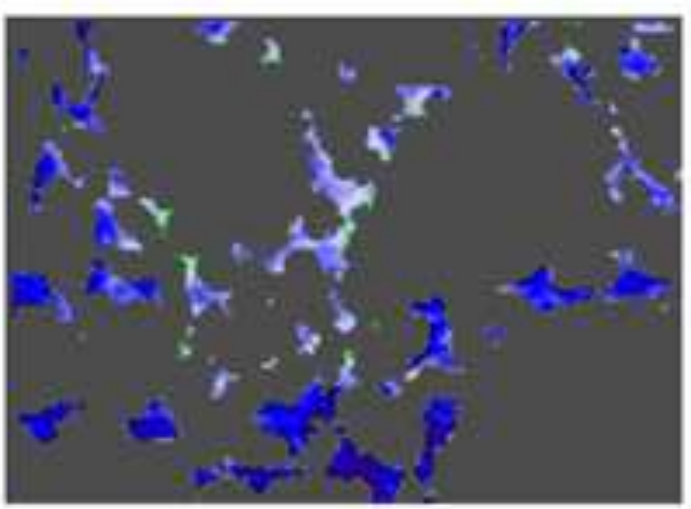

$78 \%$ SiC

$22 \% \mathrm{Si}$ 

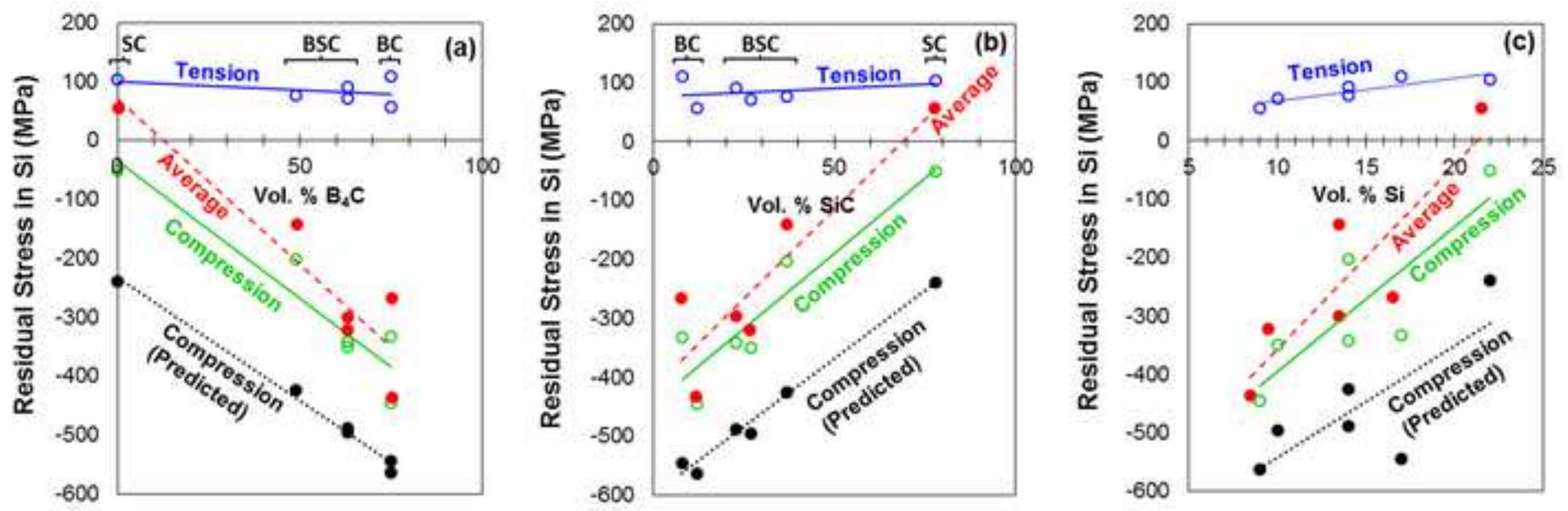

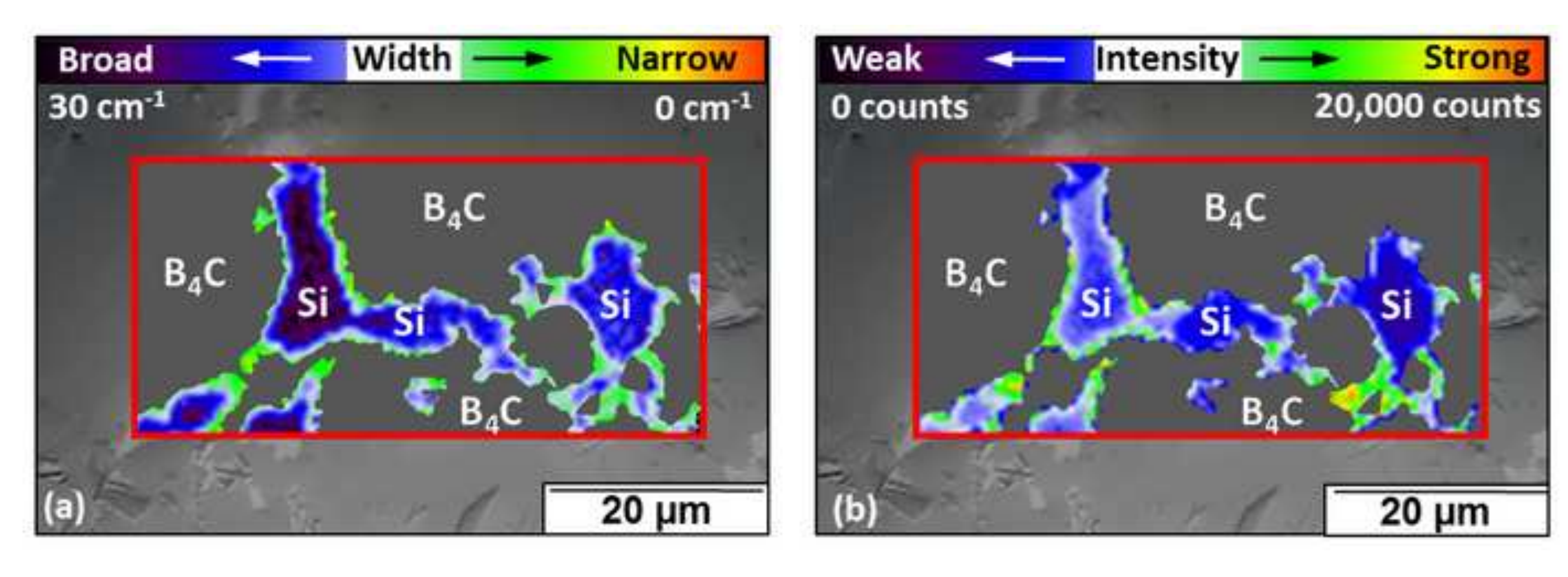

(b) $20 \mu \mathrm{m}$ 
(a) si Lump

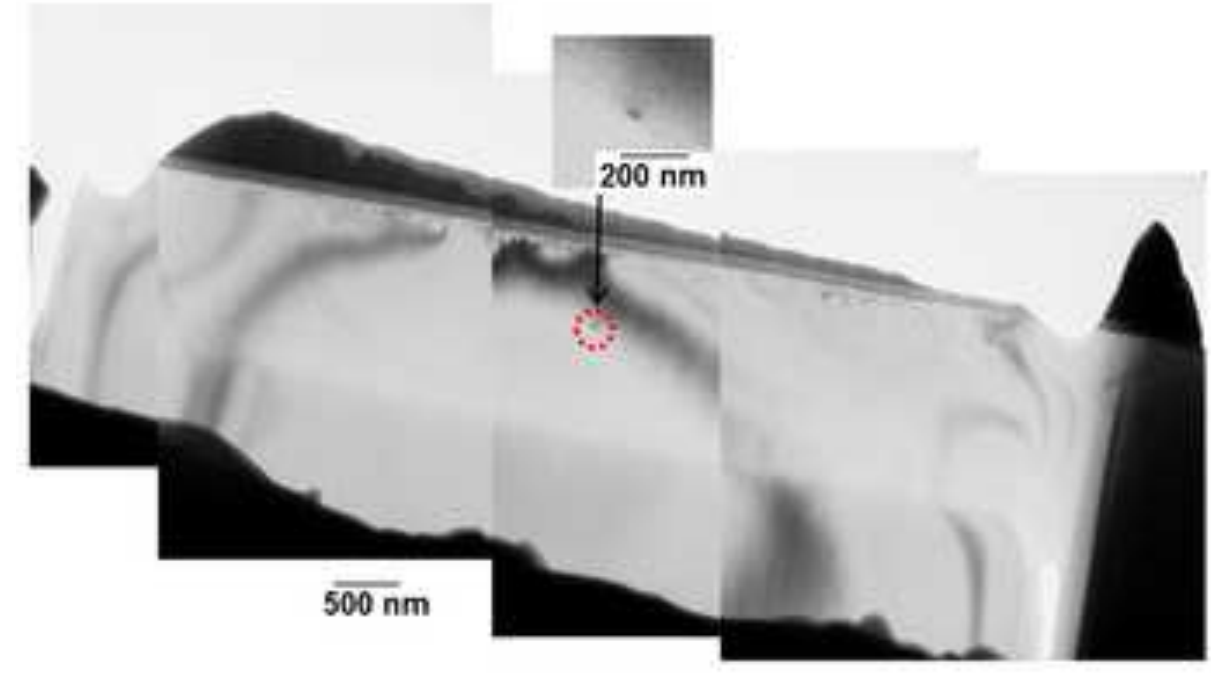

Figure 8 (b) Residual si

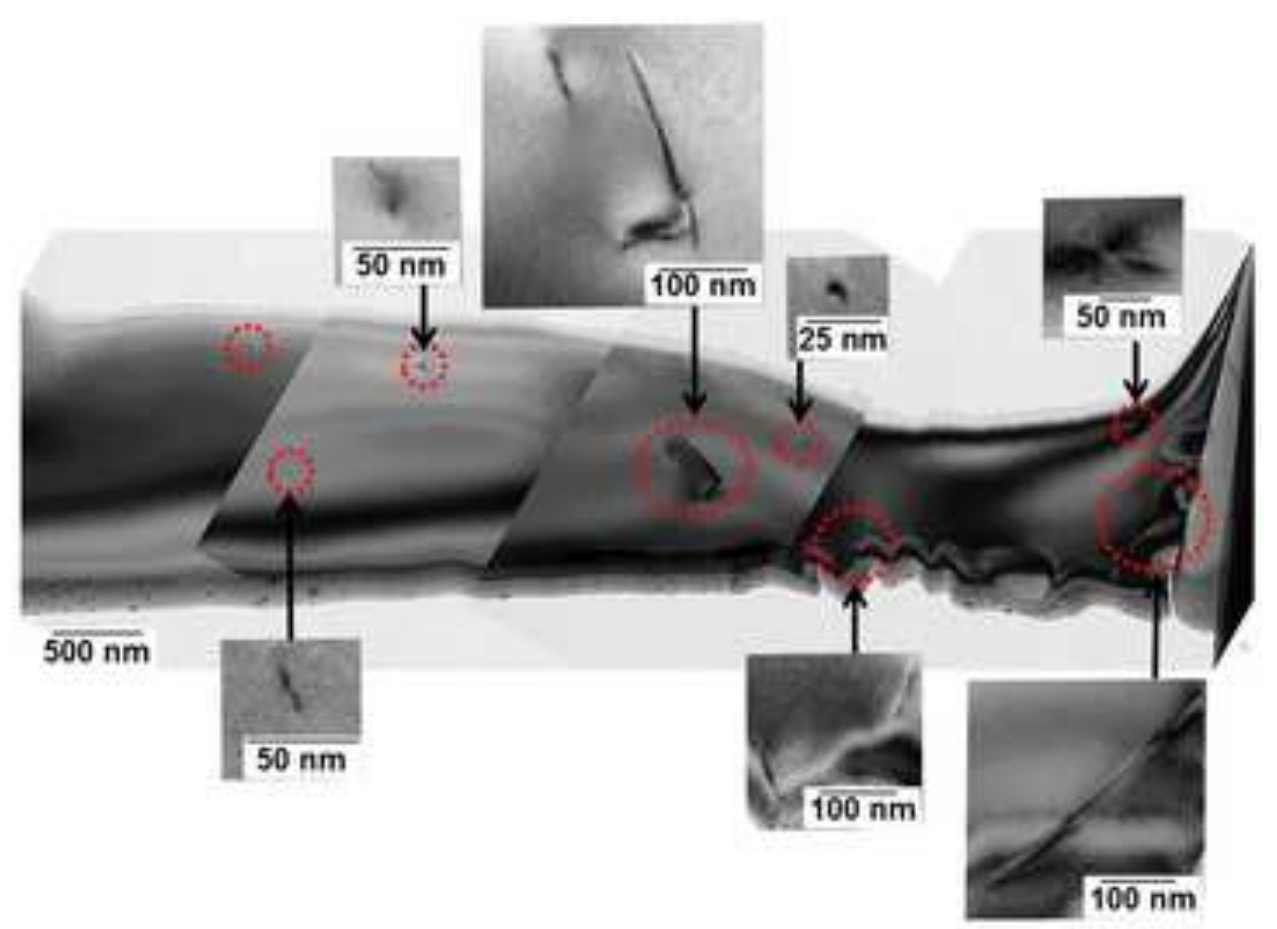




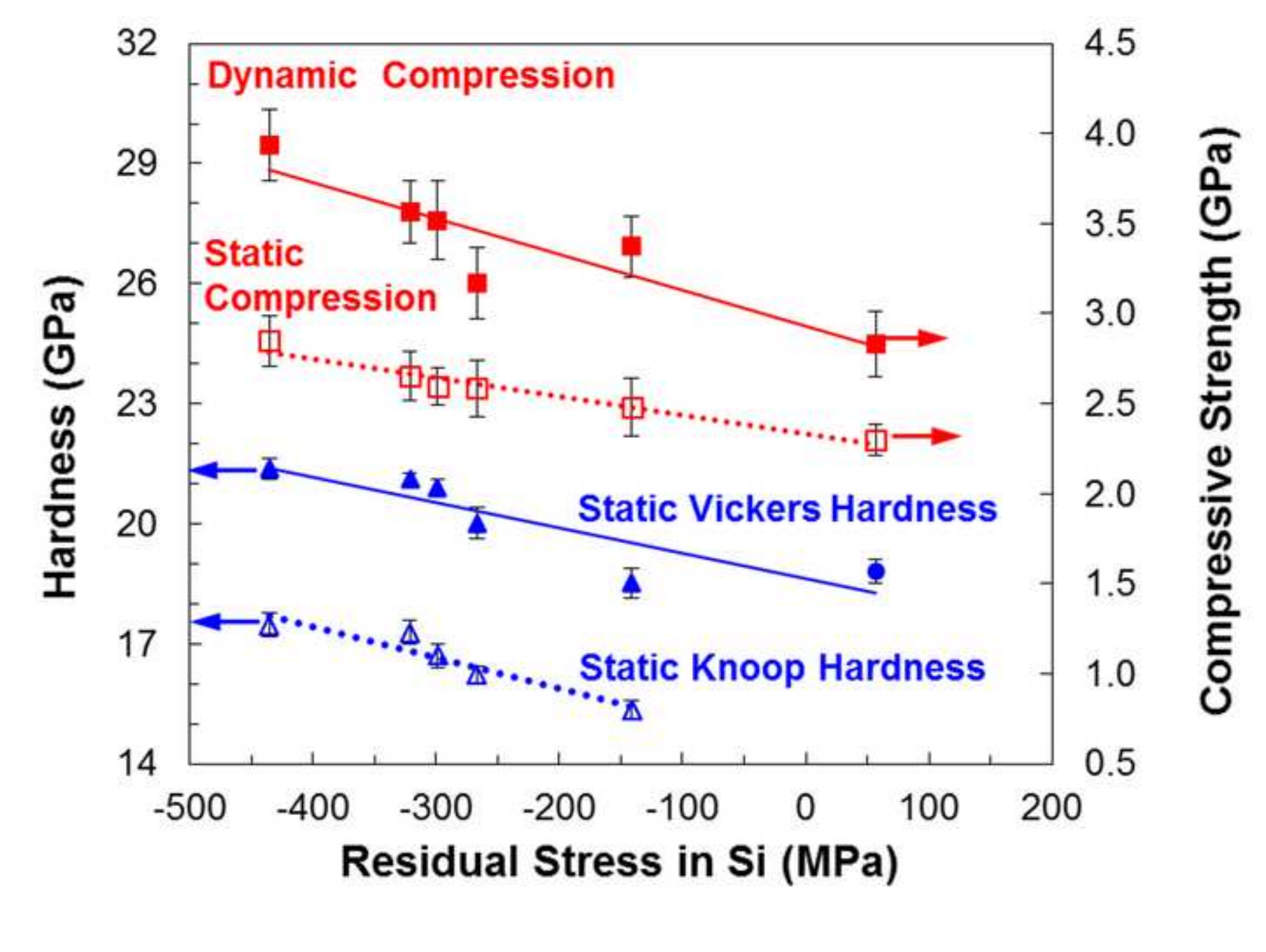

